\title{
Diabetes, Bone Density, and Fractures
}

\author{
Vijay Shivaswamy ${ }^{1,2}$, Lynn Mack¹ and Jennifer Larsen ${ }^{1,2 *}$
}

${ }^{1}$ Nebraska-Western lowa Health Care System, Omaha, NE, USA

${ }^{2}$ University of Nebraska Medical Center, Omaha, NE, USA

\begin{abstract}
All types of diabetes increase risk for osteoporosis and fracture due to multiple factors. Hyperglycemia itself may play a role, but frequent hypoglycemia, falls, hypogonadism, vitamin D deficiency, body mass index (BMI), and advanced complications may play an even larger role. Very low BMI in type 1 diabetes and elevated BMI in youth with type 2 diabetes can increase fracture risk, as well as visceral obesity in postmenopausal women. Those with advanced complications, such as peripheral and autonomic neuropathy, visual impairment, renal failure, and vascular disease are also at greater risk, in part due to greater risk for falls. Many medications can contribute to bone loss, but the thiazolidinediones are the only diabetes medications known to have a direct impact on bone mass, particularly in women. After transplant, immunosuppressant medications also contribute to fracture risk.

Bone density screening in patients with diabetes should be initiated with any known risk factors, such as at onse of menopause or other types of hypogonadism, or if part of a known high-risk sub-group, such as cystic fibrosis related diabetes or organ transplant recipients. Vitamin D screening should be performed in those with borderline low calcium, lactose intolerance, celiac sprue, post-menopause, or history of fracture. Therapy of osteoporosis should be tailored to the patient, while optimizing vitamin $\mathrm{D}$ concentration, and with special attention to renal function.

In summary, decreased bone density and fractures are more common in diabetes due to multiple factors that should be systematically considered and addressed. Bone density screening should be considered part of health care maintenance in many sub-groups of diabetes patients even though it has not yet been incorporated into the usual care guidelines for all diabetes patients.
\end{abstract}

Keywords: Diabetes; Fractures; Obesity; Bone density; Osteoporosis; Vitamin D

\begin{abstract}
Abbreviations: BMD: Bone Mineral Density; CFRD: Cystic Fibrosis Related Diabetes; DXA: Dual-Energy X-Ray Absorptiometry; NIST: National Institute of Standards and Technology; NOF: National Osteoporosis Foundation; PCOS: Polycystic Ovarian Syndrome; PPAR-gamma: Peroxisome Proliferator-Activated Receptor-gamma; RANK: Receptor Activator Of Nuclear Factor Kappa-B; TZDs: Thiazolidinediones; GFR: Glomerular Filtration Rate; NHW: NonHispanic White
\end{abstract}

\section{Introduction}

\section{Diabetes increases risk for decreased bone density and fracture}

Risk of fractures has been observed in those with type 1 and type 2 diabetes [1] Both men and women with diabetes have a higher risk for hip fractures and fractures at other sites, such as the humerus and foot, compared to those without diabetes [1-9], and bone density is less likely to fully account for the higher fracture risk [8]. Most studies have focused on risk in Caucasians with diabetes, but Japanese studies also show increased vertebral fractures in women with diabetes (Odds Ratio $=1.86$ ), despite having normal to minimally low bone density [10].

Studies that have carefully differentiated type 1 from type 2 diabetes show higher fracture risks in both types compared to the general population [4,11-13]. In an observational study of 35,444 people 50 years of age and older, adjusted relative risk of hip fracture for women with type I diabetes compared with women without diabetes was 6.9 [4]. Men with type $1 \mathrm{DM}$ had similar risk but did not reach significance. In the same study, among women 50-74 years of age with type $2 \mathrm{DM}$ for more than 5 years, the relative risk of hip fracture was 1.8 compared to those without diabetes [4]. In another case-control study where subjects diagnosed with a fracture $(\mathrm{n}=124,655)$ were compared to control subjects without fracture $(n=373,962)$, type 1 and type 2 DM were associated with increased risk of any fracture (OR 1.3 and 1.2 for type 1 and type $2 \mathrm{DM}$ respectively) and specifically hip fractures (OR 1.7 and 1.4, for type 1 and type 2 DM respectively), compared to general population [13]. However, according to a systematic review of risk of fracture in diabetics, increased risk is more consistent in those with type 1 diabetes, who are reported to have a relative risk for hip fracture from 1.7 to 12.3 [1]. In the Nurse's Health Study, a prospective study of diabetes and risk of fracture in 109,983 women aged 34-59 years, women with type 1 diabetes had a 6 -fold increase in fracture compared to the general population [14]. Spine and proximal humerus fracture are also moderately increased in type 1 diabetes $[1,11,13]$. In a casecontrol study, type 1 diabetes was associated with an increased risk of spine fractures $(\mathrm{OR}=2.5)$ compared to general population [13]. In the few available studies, women and men with type 1 diabetes have a similar increase in fracture risk. Many factors may affect the prevalence of osteopenia and osteoporosis in type 1 diabetes: age of diagnosis, duration of disease, insulin dose, BMI, and associated complications [15-18]. Those diagnosed with diabetes in either childhood or young adulthood have been reported to be less likely to attain peak bone mass after diagnosis $[15,16]$. Impact on bone density may also be sitespecific as suggested in a more recent study of 175 type 1 diabetics where lumbar (mean $Z$ score of $-0.11 \pm 1.2$ ) and femoral bone densities (mean $\mathrm{Z}$ score of $-0.32 \pm 1.4$ ) of type 1 diabetics were lower than those

${ }^{*}$ Corresponding author: Jennifer Larsen, MD, University of Nebraska Medical Center, 987878 Nebraska Medical Center, Omaha, NE 68198-7878, USA, Tel: 402559-4837; Fax: 402-559-8445; E-mail: jlarsen@unmc.edu

Received October 17, 2011; Accepted November 19, 2011; Published Novembe 24, 2011

Citation: Shivaswamy V, Mack L, Larsen J (2011) Diabetes, Bone Density, and Fractures. J Diabetes Metab S1:004. doi:10.4172/2155-6156.S1-004

Copyright: (c) 2011 Shivaswamy V, et al. This is an open-access article distributed under the terms of the Creative Commons Attribution License, which permits unrestricted use, distribution, and reproduction in any medium, provided the original author and source are credited. 
of control subjects $(0.59 \pm 1$, and $0.63 \pm 1$ respectively). The lumbar and femoral bone densities positively correlated with BMI while spine was negatively associated with daily insulin dose, and femoral bone density was positively associated with creatinine clearance. In this study, neither site correlated with age at diabetes diagnosis or A1c [18].

Patients with type 2 diabetes also have a higher risk of hip fractures than the general population [19]. A systematic review by Janghorbani, et al showed that type 2 diabetes was associated with a relative risk of 2.8 for hip fracture in men and 2.1 for women $[1,6]$. In the Women's Health Initiative Observational Study a prospective study of postmenopausal women, those with type 2 diabetes $(n=5,285)$ were compared with those without diabetes $(\mathrm{n}=88,120)$ [8]. After 7 years of follow up, women with diabetes had a $20 \%$ risk (relative risk 1.2) of fracture compared to those without diabetes. This study also showed that diabetes is a risk factor for fractures in black women, who tend to be at lower risk for fracture than non-Hispanic white women (NHW); in this study the relative risk for fracture was 1.33 for black women with diabetes compared to 1.18 for NHW women without diabetes. Fractures of the wrist and foot were only increased in those being treated with either oral antidiabetic agents or insulin $[8,9,20]$. Vertebral fracture risk was not increased in type 2 diabetes [8,13,21]. In the Nurse's Health Study, hip fracture incidence was roughly 2.5 greater in women with type 2 diabetes compared to the general population, and more than 3 times in women with type 2 diabetes treated with insulin than the general population [5].

\section{Potential Mechanisms for Risk}

Chronic hyperglycemia results in the non-enzymatic glycosylation of bone proteins, including type I collagen which may impair the biomechanical properties of bone [22]. However, there is little data correlating risk of fracture with $\mathrm{A} 1 \mathrm{C}$ in clinical studies, although duration of disease is consistently a factor [23].

Many other mechanisms have been suggested as outlined in Table 1 , such as frequent hypoglycemia associated with intensive therapy, likely because it can contribute to falls. Falls, in turn, contribute to fractures, regardless of bone density. Diabetes is associated with a higher risk of falls $[24,25]$, and insulin, in particular, increases risk of falls in the elderly [25]. Neuropathy and neuromuscular impairment are additional contributors to falls in diabetes [25-27], as well as impaired vision due to diabetic retinopathy or cataracts, stroke, chronic renal failure, and longer duration of diabetes [6,25,28,29]. Medications are recognized as factors for falls, particularly sedatives, opiates, antiepileptics, and anti-Parkinson agents [6]. In one study, functional disability, visual impairment, peripheral neuropathy, and use of longacting benzodiazepines were the strongest overall factors [23].

Commonly prescribed medications in diabetic patients can contribute or may ameliorate risk. Thiazolidinediones (TZDs), pioglitazone and rosiglitazone, are now well established to affect bone

\begin{tabular}{|l|l|l|}
\hline Mechanism & Type 1 diabetes & Type 2 diabetes \\
\hline Hyperglycemia & + & + \\
\hline Hypoglycemia & + & + \\
\hline Functional disability or falls & + & + \\
\hline Hypogonadism & + & + \\
\hline Medications & + & + \\
\hline Vitamin D deficiency & + & + \\
\hline Low BMI & + & \\
\hline High BMI/visceral obesity & + & + \\
\hline
\end{tabular}

Table 1: Proposed mechanisms for bone loss and/or fracture in diabetes. metabolism. Even after short-term treatment, rosiglitazone decreased bone formation markers and femoral neck bone mineral density (BMD) in healthy postmenopausal women [30]. Long-term use (4 yrs) reduced whole body and lumbar BMD in older women with type 2 diabetes [31]. Fracture risk was increased in randomized controlled trials of both thiazolidinediones [32-35]. The target of TZDs, PPAR-gamma, is also expressed in bone marrow cells, and acts as a molecular switch that regulates the fate of pluripotent mesenchymal stem cells, reducing their differentiation into adipocytes or osteoblasts [36]. Animal studies support the hypothesis that TZDs induce bone loss characterized by deficient osteoblast function [32,37]. Hydrochlorothiazide, commonly used for the treatment of hypertension [38], and fluvastatin [39], a statin used for prevention of vascular disease, and both prescribed in diabetes patients, have been shown to modestly improve BMD $(<1 \%$ for both hydrochlorothiazide and fluvastatin), although there have been no studies to confirm whether this benefit is realized in diabetic patients in light of all their other risk factors.

Body mass index (BMI) is another recognized variable in risk for osteoporosis and fracture. Women with low BMI are at greatest risk, as often observed in type 1 diabetes [40-43]. However, higher BMI can also be a factor in some groups, such as youth with type 2 diabetes [44], as well as postmenopausal women with visceral obesity as commonly observed in type 2 diabetes. BMI is now well recognized to be negatively associated with vitamin $\mathrm{D}$ concentration, although the mechanism for the association is not well established [45]. Nonetheless, vitamin D deficiency does contribute to low BMD, as well as muscle weakness, which can increase risk for falls. Since vitamin D concentration is negatively correlated with risk for diabetes, many individuals with type 2 diabetes have low vitamin D concentration [46].

Obesity may contribute to decreased bone density and fractures through other mechanisms, as well. Obesity is a cause of hypogonadotropic hypogonadism, and hypogonadism of any kind, in turn, contributes to osteoporosis and fractures in men and women. Thus, it is not surprising to find that hypogonadism is more common in men and women with type 2 diabetes, unrelated to duration of diabetes, glycosylated hemoglobin, or presence of microvascular complications of diabetes [47]. Dhindsa et al. showed that hypogonadism occurred in as many as one-third of men with type 2 diabetes, irrespective of the glycemic control, duration of disease, and the presence of complications of diabetes or obesity [48]. A meta-analysis and systematic review of 43 studies of 6427 men and 6974 women suggested an inverse association between plasma testosterone and risk of type 2 diabetes in men, but a linear relation between testosterone and risk of type 2 diabetes in women [49]. Both obesity and low levels of testosterone in men contribute to a pro-inflammatory profile, another potential contributor to bone loss, although testosterone treatment did not reverse the inflammatory state [50].

Hypogonadism is a particular factor for risk for bone loss and fracture in all women with diabetes and is more common in women with diabetes. Women who have type 1 diabetes and poor glucose control as well as weight loss will commonly develop amenorrhea and hypogonadotropic hypogonadism that can reverse with weight gain and improved glucose control. Prolonged amenorrhea and hypogonadism results in delayed or reduced peak bone mass. Women with type 1 diabetes are also at risk for early or premature menopause due to autoimmune anti-ovarian antibodies. Hypogonadism in type 2 diabetes is more likely to be due to obesity itself or hyperandrogenemia as can occur with polycystic ovarian syndrome (PCOS). If accompanied by amenorrhea, women with PCOS have lower spine and femoral 
neck BMD than non-amenorrhoeic PCOS patients [51]. However, a more recent study showed that spine and femoral neck BMD was not different in women with PCOS than healthy controls matched for age and BMI [52]. Thus, hypogonadism, as suggested by amenorrhea, may be a more significant factor than elevated BMI alone.

There are many other conditions that can occur as a consequence of diabetes or more common in individuals with diabetes that impacts fracture risk. Chronic kidney disease is one of the most significant as chronic kidney disease itself affects bone turnover [53]. However, diabetes further increases risk of fracture in those with chronic kidney disease or after transplantation. The risk associated with chronic kidney disease is greater for type 1 than type 2 diabetes, as shown in one trial where the relative risk for hip fracture was 6.4 vs. 1.4 for those with type 1 vs type 2 diabetes, respectively [54]. While kidney transplantation markedly improves mortality as well as kidney function, many of the immune suppression medications required to prevent rejection also increase fracture risk. Diabetes is a risk factor for fracture after solid organ transplant, along with recent use of narcotics, antidepressants, and loop diuretics [55]. While anyone who receives immune suppression agents is at increased risk for fractures, there is less data on whether individuals who develop diabetes after transplantation, called post-transplant diabetes or new onset diabetes after transplant, are at even greater risk, as observed in those with diabetes before transplant.

Type 1 diabetes predisposes the individual to other autoimmune diseases. Many of these conditions, or their treatment, further increases their risk of bone loss. Examples include celiac sprue, premature autoimmune-mediated menopause, multiple sclerosis, rheumatoid arthritis, lupus erythematosis, and hyperthyroidism or excessive thyroid replacement for hypothyroidism.

Specific types of diabetes are of particular risk for osteoporosis and fracture: diabetic patients following transplantation as discussed above, diabetes following pancreatectomy with exocrine insufficiency, and cystic fibrosis related diabetes (CFRD). Pancreatic exocrine insufficiency requires treatment to optimize fat absorption. Since vitamin $\mathrm{D}$ absorption is also affected, these patients should be routinely coached to take their pancreatic enzymes and their vitamin D should be monitored frequently and supplemented as indicated.

Cystic fibrosis related diabetes (CFRD) develops in 10\% of individuals with cystic fibrosis [56]. Patients with cystic fibrosis have multiple risk factors for reduced bone mineral accrual and enhanced bone loss: vitamin $\mathrm{D}$ deficiency due to fat malabsorption, malnutrition, inflammation, hypogonadism, inactivity, and frequent treatment with exogenous glucocorticoids. While CFRD is distinct from type 1 and type 2 diabetes, many of the same mechanisms contribute to their risk: hyperglycemia, chronic infection with increased inflammatory cytokines, fat malabsorption with risk of vitamin D deficiency, reduced physical activity during times of exacerbation, and hypogonadism, all of which may be additive to increase their overall fracture risk. No studies have established the relative impact of the multiple risks for bone loss in this population. However, amenorrhea appears to be a particular risk for low bone mass and fracture in women with CFRD [56]. Periodic bone density screening and regular monitoring of vitamin $\mathrm{D}$ with initiation of vitamin $\mathrm{D}$ supplementation as indicated to achieve optimal concentrations should be considered in both men and women, as per the Guide to Bone Health and Disease in Cystic Fibrosis [56].

\section{Screening for Decreased Bone Density: When and How}

- The National Osteoporosis Foundation (NOF) and American
Association of Clinical Endocrinologists (AACE) have made general recommendations for who should be considered for bone density screening with dual energy $\mathrm{x}$-ray absorptiometry (DXA) [57]. Where data supports it, we have added modifiers specific to diabetes patients to the NOF guidelines as shown in italics below:Women age 65 and older and men age 70 and older, regardless of clinical risk factors.

- Younger postmenopausal women and men age 50 to 69 about whom you have concern based on their clinical risk factor profile, such as frequent amenorrhea during premenopausal years, hypogonadism in men, visceral obesity in women, decreased renal function, history of celiac sprue, or medications known to affect risk such as treatment with TZDs or corticosteroids.

- Women in the menopausal transition if there is a specific risk factor associated with increased fracture risk such as low body weight, prior low-trauma fracture or high-risk medication as described above.

\section{- Adults who have a fracture after age 50.}

- Adults with a condition (e.g., rheumatoid arthritis) or taking a medication (e.g., $\geq 5 \mathrm{mg}$ prednisone/day or equivalent for $\geq 3$ months) associated with low bone mass or bone loss, such as posttransplant, post-pancreatectomy, or with cystic fibrosis related diabetes.

- Anyone being considered for pharmacologic therapy for osteoporosis.

- Anyone being treated for osteoporosis, to monitor treatment effect.

- Anyone not receiving therapy in whom evidence of bone loss would lead to treatment.

- Postmenopausal women discontinuing estrogen.

The NOF recommendations for calcium and vitamin D supplements are shown in Table 2. Where vitamin D deficiency is common or severe, such as those with celiac sprue, cystic fibrosis related diabetes, postenteric diversion gastric bypass procedures, or other causes of exocrine insufficiency, including post-pancreatectomy, regular measurements should be performed. Ensuring adequate intake of calcium and vitamin $\mathrm{D}$ with achievement of the recommended daily allowances for each is important even before considering other treatments [57].

\section{Recommendations for Anabolic and Anti-Resorptive Therapies}

Prior to outlining a treatment plan, it is important to evaluate the

\begin{tabular}{|l|l|l|}
\hline & Calcium (Daily) & Vitamin D (Daily) \\
\hline Children \& Adolescents & & \\
\hline 1 through 3 years & $500 \mathrm{mg}$ & $400 \mathrm{IU}^{*}$ \\
\hline 4 through 8 years & $800 \mathrm{mg}$ & $400 \mathrm{IU}^{*}$ \\
\hline 9 through 18 years & $1,300 \mathrm{mg}$ & $400 \mathrm{IU}^{*}$ \\
\hline Adult Women \& Men & & \\
\hline 19 through 49 years & $1,000 \mathrm{mg}$ & $400-800 \mathrm{IU}$ \\
\hline 50 years and over & $1,200 \mathrm{mg}$ & $800-1000 \mathrm{IU}$ \\
\hline Pregnant \& Breastfeeding Women & & \\
\hline 18 years and under & $1,300 \mathrm{mg}$ & $400-800 \mathrm{IU}$ \\
\hline 19 years and over & $1,000 \mathrm{mg}$ & $400-800 \mathrm{IU}$ \\
\hline
\end{tabular}

*NOF does not have specific vitamin $D$ recommendations for these age groups These are the recommendations of the American Academy of Pediatrics

Table 2: National Osteoporosis Foundation 2010 Calcium and Vitamin D Recommendations [57] 
patient for secondary, treatable causes of osteoporosis with serum calcium, albumin, serum creatinine with estimated glomerular filtration rate (GFR), phosphate, 25-hydroxy-vitamin $\mathrm{D}$, and PTH concentration for any individual with low or high calcium. Measurement of 25-hydroxy-vitamin $\mathrm{D}$ should be performed in a reference laboratory that is using the new National Institute of Standards and Technology (NIST) standard [58]. Testing for other secondary causes of osteoporosis (e.g., thyroid function tests, serum protein electrophoresis), should be tailored to the individual based on specific characteristics. Separately, the individual should be examined for factors that could contribute to falls, such as peripheral neuropathy, muscle weakness, orthostasis, or low vision. A discussion of prevention measures, such as removing throw rugs that can slip, avoiding travel outside after ice or snow, and wearing low-heeled shoes with non-slip soles should be undertaken. Regular weight-bearing exercise maintains muscle strength as well as BMD. Thiazolidinediones should be discontinued in any woman identified with osteoporosis when alternatives can be considered.

When a pharmacologic therapy is warranted, the benefits of therapy, whether with anti-resorptive or anabolic agents, need to be weighed against the risks. Patients with diabetes who otherwise meet the indications for treatment based on bone density and fracture risk profile can safely be treated with bisphosphonates such as alendronate $\left(\right.$ Fosamax $^{\mathbb{R}}$ ), risedronate $\left(\right.$ Actonel $\left.^{\mathbb{R}}\right)$, ibandronate $\left(\right.$ Boniva $\left.^{\circledR}\right)$, or zoledronic acid $\left(\right.$ Reclast $\left.^{\mathbb{R}}\right)$, as long as they have an estimated GFR above $35 \mathrm{ml} / \mathrm{min}$. Patients who plan to undergo either a root canal or tooth extraction in the immediate future should stop the bisphosphonate medication for 12 weeks before and after the dental procedure to reduce risk of osteonecrosis of the jaw [59]. A drug holiday for one to two years should be planned after around 5 years of bisphosphonate therapy to reduce over suppression of bone turnover, now thought to be the main risk factor for sub-trochanteric fracture $[60,61]$. Teriparatide $\left(\right.$ Forteo $\left.^{\circledR}\right)$ is indicated for treatment of women with postmenopausal osteoporosis and in men with idiopathic or hypogonadal osteoporosis who are at high risk of fracture or who have failed or been intolerant of previous osteoporosis therapy, with the exception of those who are at increased risk of osteosarcoma (patients with Paget disease of bone, open epiphyses, history of skeletal irradiation or unexplained elevation of alkaline phosphatase of skeletal origin) [61]. The newest treatment available is the monoclonal antibody focused on the RANK ligand inhibitor, denosumab (Prolia ${ }^{\circledR}$ ), which has been used safely in renal failure so may be of particular benefit in this setting.

\section{Conclusions}

Diabetes patients are at increased risk for fractures. While hyperglycemia may contribute, many other factors may also be involved, including BMI, diabetic complications, associated autoimmune diseases, hypogonadism, falls, hypoglycemia, and medications. Type 1 diabetes is associated with greater risk of fractures compared to type 2 diabetes or general population. However, youth with obesity, as well as postmenopausal women with visceral obesity, are also at increased risk for fracture of the humerus and ankle. Other specific types of diabetes at particular risk include those with cystic fibrosis related diabetes and those with diabetes who are receiving an organ transplant. Because of the greater overall risk for bone loss and fracture in diabetes, bone density screening and treatment should be considered for those with low BMI $\left(<19 \mathrm{~kg} / \mathrm{m}^{2}\right)$, hypogonadism, significant neuromuscular dysfunction, frequent severe hypoglycemia or other autonomic neuropathies that increase their risk of falls, or have concomitant diseases that further increase their risk such as celiac sprue, strong family history of osteoporosis, corticosteroids or other immunosuppressant medications, seizure disorder or treatment with many anti-seizure medications.

Measurement of 25-hydroxy-vitamin D, deficiency of which is common in those with obesity, celiac sprue, or fat malabsorption, should be considered in anyone considered at particular risk, with initiation of vitamin D supplementation alongside other osteoporosis treatments. While frequency of bone density surveillance has not been well established in diabetes, once osteoporosis has been identified, follow-up screening should continue at least every two years while on treatment to confirm stability of bone density, or more frequently in certain clinical situations.

\section{References}

1. Janghorbani M, Van Dam RM, Willett WC, Hu FB (2007) Systematic Review of Type 1 and Type 2 Diabetes Mellitus and Risk of Fracture. Am J Epidemiol 166 495-505.

2. Ahmed LA, Joakimsen RM, Berntsen GK, Fonnebo V, Schirmer H (2006) Diabetes Mellitus and the Risk of Non-Vertebral Fractures: The Tromso Study. Osteoporos Int 17: 495-500.

3. Cummings SR, Nevitt MC, Browner WS, Stone K, Fox KM, et al. (1995) Risk Factors for Hip Fracture in White Women. Study of Osteoporotic Fractures Research Group. N Engl J Med 332: 767-773.

4. Forsen L, Meyer HE, Midthjell K, Edna TH (1999) Diabetes Mellitus and the Incidence of Hip Fracture: Results from the Nord-Trondelag Health Survey. Diabetologia 42: 920-925.

5. Janghorbani M, Hu FB, Willett WC, Li TY, Manson JE, et al. (2007) Prospective Study of Type 1 and Type 2 Diabetes and Risk of Stroke Subtypes: The Nurses Health Study. Diabetes Care 30: 1730-1735

6. Lipscombe LL, Jamal SA, Booth GL, Hawker GA (2007) The Risk of Hip Fractures in Older Individuals with Diabetes: A Population-Based Study. Diabetes Care 30: 835-841.

7. Michaelsson K, Holmberg L, Mallmin H, Sorensen S, Wolk A, et al. (1995) Die and Hip Fracture Risk: A Case-Control Study. Study Group of the Multiple Risk Survey on Swedish Women for Eating Assessment. Int J Epidemiol 24: 771782

8. Bonds DE, Larson JC, Schwartz AV, Strotmeyer ES, Robbins J, et al. (2006) Risk of Fracture in Women with Type 2 Diabetes: The Women's Health Initiative Observational Study. J Clin Endocrinol Metab 91: 3404-3410

9. Schwartz AV, Sellmeyer DE, Ensrud KE, Cauley JA, Tabor HK, et al. (2001) Older Women with Diabetes have an Increased Risk of Fracture: A Prospective Study. J Clin Endocrinol Metab 86: 32-38.

10. Yamamoto M, Yamaguchi T, Yamauchi M, Kaji H, Sugimoto T (2009) Diabetic Patients have an Increased Risk of Vertebral Fractures Independent of BMD Or Diabetic Complications. J Bone Miner Res 24: 702-729.

11. Kelsey JL, Browner WS, Seeley DG, Nevitt MC, Cummings SR (1992) Risk Factors for Fractures of the Distal Forearm and Proximal Humerus. the Study of Osteoporotic Fractures Research Group. Am J Epidemiol 135: 477-489.

12. Miao J, Brismar K, Nyren O, Ugarph-Morawski A, Ye W (2005) Elevated Hip Fracture Risk in Type 1 Diabetic Patients: A Population-Based Cohort Study in Sweden. Diabetes Care 28: 2850-2855.

13. Vestergaard P, Rejnmark L, Mosekilde L (2005) Relative Fracture Risk in Patients with Diabetes Mellitus, and the Impact of Insulin and Oral Antidiabetic Medication on Relative Fracture Risk. Diabetologia 48: 1292-1299

14. Janghorbani M, Feskanich D, Willett WC, Hu F (2006) Prospective Study of Diabetes and Risk of Hip Fracture: The Nurses' Health Study. Diabetes Care 29:1573-1578.

15. Leger J, Marinovic D, Alberti C, Dorgeret S, Chevenne D, et al. (2006) Lower Bone Mineral Content in Children with Type 1 Diabetes Mellitus is Linked to Female Sex, Low Insulin-Like Growth Factor Type I Levels, and High Insulin Requirement. J Clin Endocrinol Metab 91: 3947-3953.

16. Moyer-Mileur LJ, Slater H, Jordan KC, Murray MA (2008) IGF-1 and IGFBinding Proteins and Bone Mass, Geometry, and Strength: Relation to Metabolic Control in Adolescent Girls with Type 1 Diabetes. J Bone Miner Res 23: 1884-1891. 
17. Yaturu S (2009) Diabetes and Skeletal Health. J Diabetes 1: 246-254.

18. Eller-Vainicher C, Zhukouskaya VV, Tolkachev YV, Koritko SS, Cairoli E, et al (2011) Low Bone Mineral Density and its Predictors in Type 1 Diabetic Patients Evaluated by the Classic Statistics and Artificial Neural Network Analysis. Diabetes Care 34: 2186-2191.

19. Khazai NB, Beck GR Jr, Umpierrez GE (2009) Diabetes and Fractures: An Overshadowed Association. Curr Opin Endocrinol Diabetes Obes16: 435-445.

20. de L, van der Klift M, de Laet CE, van Daele PL, Hofman A, et al. (2005) Bone Mineral Density and Fracture Risk in Type-2 Diabetes Mellitus: The Rotterdam Study. Osteoporos Int 16: 1713-1720.

21. Strotmeyer ES, Cauley JA, Schwartz AV, Nevitt MC, Resnick HE, et al. (2005) Nontraumatic Fracture Risk with Diabetes Mellitus and Impaired Fasting Glucose in Older White and Black Adults: The Health, Aging, and Body Composition Study. Arch Intern Med 165: 1612-1617.

22. Vashishth D, Gibson GJ, Khoury JI, Schaffler MB, Kimura J, et al. (2001) Influence of Nonenzymatic Glycation on Biomechanical Properties of Cortical Bone. Bone 28: 195-201.

23. Chau DL, Edelman SV, Chandran M (2003) Osteoporosis and Diabetes. Curr Diab Rep 3: 37-42.

24. Maurer MS, Burcham J, Cheng H (2005) Diabetes Mellitus is Associated with an Increased Risk of Falls in Elderly Residents of a Long-Term Care Facility. J Gerontol A Biol Sci Med Sci 60: 1157-1162.

25. Schwartz AV, Vittinghoff E, Sellmeyer DE, Feingold KR, de Rekeneire N, et al. (2008) Diabetes-Related Complications, Glycemic Control, and Falls in Older Adults. Diabetes Care 31:391-396.

26. Greenspan SL, Myers ER, Kiel DP, Parker RA, Hayes WC, et al. (1998) Fal Direction, Bone Mineral Density, and Function: Risk Factors for Hip Fracture in Frail Nursing Home Elderly. Am J Med 104: 539-545.

27. Greenspan SL, Myers ER, Maitland LA, Resnick NM, Hayes WC (1994) Fall Severity and Bone Mineral Density as Risk Factors for Hip Fracture in Ambulatory Elderly. JAMA 271: 128-133.

28. Ivers RQ, Cumming RG, Mitchell P, Peduto AJ (2001) Diabetes and Risk of Fracture: The Blue Mountains Eye Study. Diabetes Care 24: 1198-1203.

29. Kanis J, Oden A, Johnell O (2001) Acute and Long-Term Increase in Fracture Risk After Hospitalization for Stroke. Stroke 32: 702-706.

30. Grey A, Bolland M, Gamble G, Wattie D, Horne A, et al. (2007) The Peroxisome Proliferator-Activated Receptor-Gamma Agonist Rosiglitazone Decreases Bone Formation and Bone Mineral Density in Healthy Postmenopausa Women: A Randomized, Controlled Trial. J Clin Endocrinol Metab 92: 13051310

31. Schwartz AV, Sellmeyer DE, Vittinghoff E, Palermo L, Lecka-Czernik B, et al (2006) Thiazolidinedione use and Bone Loss in Older Diabetic Adults. J Clin Endocrinol Metab 91: 3349-3354

32. Home PD, Pocock SJ, Beck-Nielsen H, Curtis PS, Gomis R, et al. (2009) Rosiglitazone Evaluated for Cardiovascular Outcomes in Oral Agent Combination Therapy for Type 2 Diabetes (RECORD): A Multicentre, Randomised, Open-Label Trial. Lancet 373: 2125-2135.

33. Dormandy J, Bhattacharya M, van Troostenburg de Bruyn AR (2009) Safety and Tolerability of Pioglitazone in High-Risk Patients with Type 2 Diabetes: An Overview of Data from PROactive. Drug Saf 32: 187-202.

34. Kahn SE, Zinman B, Lachin JM, Haffner SM, Herman WH, et al. (2008) Rosiglitazone-Associated Fractures in Type 2 Diabetes: An Analysis from A Diabetes Outcome Progression Trial (ADOPT). Diabetes Care 31: 845-851.

35. Loke YK, Singh S, Furberg CD (2009) Long-Term use of Thiazolidinediones and Fractures in Type 2 Diabetes: A Meta-Analysis. CMAJ 180: 32-39.

36. Yamaguchi T, Sugimoto T (2011). Bone Metabolism and Fracture Risk in Type 2 Diabetes Mellitus [Review]. Endocr J 58: 613-624.

37. Rzonca SO, Suva LJ, Gaddy D, Montague DC, Lecka-Czernik B (2004) Bone is a Target for the Antidiabetic Compound Rosiglitazone. Endocrinology 145 401-406.
38. Bolland MJ, Ames RW, Horne AM, Orr-Walker BJ, Gamble GD, et al. (2007) The Effect of Treatment with a Thiazide Diuretic for 4 Years on Bone Density in Normal Postmenopausal Women. Osteoporos Int 18: 479-486.

39. Gotoh M, Mizuno K, Ono Y, Takahashi M (2011) Fluvastatin Increases Bone Mineral Density in Postmenopausal Women. Fukushima J Med Sci 57:19-27.

40. De Laet C, Kanis JA, Oden A, Johanson H, Johnell O, et al. (2005) Body Mass Index as a Predictor of Fracture Risk: A Meta-Analysis. Osteoporos Int 16 1330-1338.

41. Ensrud KE, Ewing SK, Stone KL, Cauley JA, Bowman PJ, et al. (2003) Intentional and Unintentional Weight Loss Increase Bone Loss and Hip Fracture Risk in Older Women. J Am Geriatr Soc 51:1740-1747.

42. Kaptoge S, Welch A, McTaggart A, Mulligan A, Dalzell N, et al. (2003) Effects of Dietary Nutrients and Food Groups on Bone Loss from the Proximal Femur in Men and Women in the 7th and 8th Decades of Age. Osteoporos Int 14: 418 428.

43. Saneshige S (1992) [Spinal Bone Mineral Density in the Female Diabetic Patients]. Nihon Ronen Igakkai Zasshi 29: 864-873.

44. Dimitri P, Bishop N, Walsh JS, Eastell R (2011) Obesity is a Risk Factor for Fracture in Children but is Protective Against Fracture in Adults: A Paradox. Bone.

45. Brock K, Huang WY, Fraser DR, Ke L, Tseng M, et al. (2010) Low Vitamin D Status is Associated with Physical Inactivity, Obesity and Low Vitamin D Intake in a Large US Sample of Healthy Middle-Aged Men and Women. J Steroid Biochem Mol Biol 121: 462-466.

46. Baz-Hecht M, Goldfine AB (2010) The Impact of Vitamin D Deficiency on Diabetes and Cardiovascular Risk. Curr Opin Endocrinol Diabetes Obes 17: 113-119.

47. Dandona P, Dhindsa S, Chaudhuri A, Bhatia V, Topiwala S (2008) Hypogonadotrophic Hypogonadism in Type 2 Diabetes. Aging Male 11: 107117.

48. Dhindsa S, Prabhakar S, Sethi M, Bandyopadhyay A, Chaudhuri A, et al (2004) Frequent Occurrence of Hypogonadotropic Hypogonadism in Type 2 Diabetes. J Clin Endocrinol Metab 89: 5462-5468.

49. Ding EL, Song Y, Malik VS, Liu S (2006) Sex Differences of Endogenous Sex Hormones and Risk of Type 2 Diabetes: A Systematic Review and MetaAnalysis. JAMA 295: 1288-1299.

50. Kapoor D, Clarke S, Stanworth R, Channer KS, Jones TH (2007) The Effect of Testosterone Replacement Therapy on Adipocytokines and C-Reactive Protein in Hypogonadal Men with Type 2 Diabetes. Eur J Endocrinol 156: 595-602.

51. Adami S, Zamberlan N, Castello R, Tosi F, Gatti D, et al. (1998) Effect of Hyperandrogenism and Menstrual Cycle Abnormalities on Bone Mass and Bone Turnover in Young Women. Clin Endocrinol (Oxf) 48: 169-173.

52. Noyan V, Yucel A, Sagsoz N (2004) The Association of Bone Mineral Density with Insulin Resistance in Patients with Polycystic Ovary Syndrome. Eur J Obstet Gynecol Reprod Biol 115: 200-205

53. Jamal SA, West SL, Miller PD (2011) Fracture Risk Assessment in Patients with Chronic Kidney Disease. Osteoporos Int Sep 8.

54. Vestergaard P, Rejnmark L, Mosekilde L (2009) Diabetes and its Complications and their Relationship with Risk of Fractures in Type 1 and 2 Diabetes. Calcif Tissue Int 84: 45-55.

55. Rakel A, Sheehy O, Rahme E, Lelorier J (2007) Does Diabetes Increase the Risk for Fractures After Solid Organ Transplantation? A Nested Case-Control Study. J Bone Miner Res 22: 1878-1884.

56. Aris RM, Merkel PA, Bachrach LK, Borowitz DS, Boyle MP, et al. (2005) Guide to Bone Health and Disease in Cystic Fibrosis. J Clin Endocrinol Metab 90: 1888-1896.

57. National Osteoporosis Foundation, Washington, DC (2010) Clinician's Guide to Prevention and Treatment of Osteoporosis, National Osteoporosis Foundation.

58. Yetley EA, Pfeiffer CM, Schleicher RL, Phinney KW, Lacher DA, et al. (2010) NHANES Monitoring of Serum 25-Hydroxyvitamin D: A Roundtable Summary J Nutr

59. Surgeons AAoM (2009) Position Statement from the American Association of Maxillofacial Surgeons. 
60. Shane E, Burr D, Ebeling PR, Abrahamsen B, Adler RA, et al. (2010) Atypical Subtrochanteric and Diaphyseal Femoral Fractures: Report of a Task Force of the American Society for Bone and Mineral Research. J Bone Miner Res Nov 25: $2267-2294$
61. Watts NB, Bilezikian JP, Camacho PM, Greenspan SL, Harris ST, et al. (2010) American Association of Clinical Endocrinologists Medical Guidelines for Clinical Practice for the Diagnosis and Treatment of Postmenopausal Osteoporosis. Endocr Pract Nov-Dec 16 Suppl 3: 1-37.

This article was originally published in a special issue, Diabetic Osteoporosis handled by Editor(s). Dr. Laura McCabe, Michigan State University, USA 